\title{
Peningkatan Kinerja Pegawai Ditinjau dari Aspek Lingkungan Kerja pada Kantor Sekretariat Dewan Perwakilan Rakyat Daerah Kota Sibolga
}

Yacub Hutabarat

STIE Al-Washliyah Sibolga

Jimmy Hendrix Sinaga

STIE Al-Washliyah Sibolga

\begin{abstract}
Abstrak Secara umum penelitian ini bertujuan untuk mengetahui pengaruh lingkungan kerjaterhadap kinerja pegawaipada Kantor Sekretariat Dewan Perwakilan Rakyat Daerah Kota Sibolga. Desain penelitian yang digunakan dalam penelitian ini adalah desain penelitian deskriptif korelasional, yang menguraikan dan memberikan penjelasan tentang hubungan antara variabel $\mathrm{X}$ (independen) sebagai variabel bebas yang mempengaruhi dan variabel $\mathrm{Y}$ (dependen) sebagai variabel terikat yang dipengaruhi. Dimana yang menjadi variabel bebas adalah lingkungan kerja dan variabel terikat adalah kinerja pegawai.Dari hasil perhitungan statistikal diketahui bahwa kedua variabel mempunyai hubungan sebesar 0,69 dan apabila diinterprestasikan dalam skala nilai maka dikategorikan cukup, Selanjutnya dari hasil persamaan regresi, diperoleh persamaan $\mathrm{Y}=14,40+0,58 \mathrm{X}$ yang menunjukkan pengaruh lingkungan kerja terhadap kinerja pegawai. Kemudian besarnya pengaruh lingkungan kerja terhadap kinerja pegawai sebesar 0,80 apabila variabel lingkungan kerja ditambah satu satuan. Uji hipotesis yang dilakukan menunjukkan ada pengaruh lingkungan kerja terhadap kinerja pegawai, dimana $\mathrm{t}$ hitung $>\mathrm{t}$ tabel $(5,4307>2,0395)$.Berdasarkan koefisien determinasi yang diperoleh sebesar $48 \%$, hal ini bermakna bahwa variabel kinerja pegawai ditentukan variabel lingkungan kerja dan sisanya52\% ditentukan oleh variabel-variabel lain yang tidak dibahas oleh penulis dalam penelitian ini.
\end{abstract}

Kata Kunci Kinerja, Lingkungan Kerja, dan Regresi Linear

\section{PENDAHULUAN}

Organisasi dalam rangka mengembangkan sumber daya manusia perlu memperhatikan lingkungan kerja pegawainya. Suatu organisasi tentu saja membutuhkan pegawai yang mampu bertanggung jawab atas pekerjaannya dan juga terhadap organisasi atau perusahaan 
tempat mereka bekerja. Dengan demikian pihak organisasi atau perusahaan harus berusaha agar pegawai memperoleh peningkatan kinerja. Pihak organisasi atau perusahaan harus dapat memahami perilaku pegawai agar kebutuhan-kebutuhan pegawai dapat terpenuhi, sehingga lingkungan kerja pegawai dapat terpelihara. Dengan terpelihara dan terjaganya lingkungan kerja pegawai, maka akan mendorong mereka untuk bekerja dengan semangat kerja yang tinggi dan pada akhirnya akan membantu secara efektif dan efisien pihak organisasi/perusahaan dalam mencapai tujuan yang diinginkan.

Salah satu faktor yang mempengaruhi peningkatan kinerja adalah lingkungan kerja. Apabila kondisi lingkungan kerja baik, maka hal tersebut dapat memacu timbulnya rasa puas dalam diri pegawai yang pada akhirnya dapat memberi pengaruh positif terhadap kepuasan kerja pegawai, begitu sebaliknya apabila kondisi lingkungan kerja buruk, maka pegawai tidak akan mempunyai kepuasan dalam bekerja. Lingkungan kerja menyangkut segala sesuatu yang berada di sekitar pekerjaan dan yang dapat mempengaruhi pegawai dalam melaksanakan tugas antara lain adalah pelayanan pegawai kepada publik, kondisi kerja, hubungan pegawai di dalam kantor yang bersangkutan. Lingkungan kerja yang baik, yaitu lingkungan kerja yang menyenangkan, dan yang dapat memberikan rasa aman adalah lingkungan kerja yang didambakan oleh semua orang.

Keadaaan lingkungan kerja pada Kantor Sekretariat Dewan Perwakilan Rakyat Daerah Kota Sibolga cenderung membosankan, dan kondisi udara dalam lingkungan kerja yang kurang bersih dan sehat. Hal ini di sebabkan karena sebagian pegawai bekerja di luar ruangan tepatnya di area halaman gedung kantor, serta kurangnya kegiatan yang dapat menambah keakraban sesama pegawai seperti, olahraga bersama. Oleh karena itu pihak pimpinan kantor perlu menciptakan dan memelihara lingkungan kerja yang baik, karena lingkungan kerja yang baik akan dapat membuat pegawai bekerja lebih giat dan secara otomatis dapat meningkatkan kinerja pegawai.

Berdasarkan dari uraian diatas, maka penulis tertarik untuk melakukan penelitian di Kantor Sekretariat Dewan Perwakilan Rakyat Daerah Kota Sibolga dan menuangkannya dalam suatu skripsi yang berjudul Peningkatan Kinerja Pegawai Ditinjau Dari Aspek Lingkungan Kerja Pada Kantor Sekretariat Dewan Perwakilan Rakyat Daerah Kota Sibolga.

\section{TINJAUAN PUSTAKA}

A. Kinerja

Menurut Hasibuan Malayu, (2009 : 79) bahwa “ Kinerja seorang pegawai pada dasarnya adalah "Suatu hasil kerja yang dicapai seseorang dalam melaksanakan tugas-tugas yang dibebankan kepadanya yang didasarkan atas kecakapan, pengalaman dan kesungguhan serta waktu".

Menurut Ranupanjodo Heidrachman dan Husnan Saud (2009 : 243) kinerja adalah "Output dari hasil kerja dari fungsi pekerjaan dalam suatu periode waktu tertentu".

Sedangkan menurut Mangkunegara (2009 : 67)mendefinisikan kinerja adalah "Hasil kerja secara kualitas dan kuantitas yang dicapai oleh seseorang pegawai dalam melaksanakan tugasnya sesuai dengan tanggung jawab yang diberikan kepadanya”.

\section{B. Lingkungan Kerja}

Pendapat Sopiah (2008: 67) yang menyatakan bahwa "Lingkungan kerja dapat mempengaruhi kinerja seseorang". Beberapa pakar mengemukakan pengertian tentang lingkungan kerja, antara lain: Menurut Veitzhal (2004:165) bahwa lingkungan kerja adalah "Keseluruhan sarana dan prasarana yang ada di sekitar pegawai yang sedang melakukan 
pekerjaan itu sendiri”. Lingkungan kerja ini meliputi: tempat kerja, fasilitas dan alat bantu pekerjaan, kebersihan, pencahayaan, ketenangan termasuk juga hubungan antara orang-orang yang ada di tempat tersebut.

Menurut Nitisemito (2006: 183) lingkungan kerja adalah "Segala sesuatu yang ada di sekitar para pekerja dan yang dapat mempengaruhi dirinya dalam menjalankan tugas-tugas yang diberikan, misalnya kebersihan, musik dan lain-lain". Pendapat lain mengenai pengertian lingkungan kerja diungkapkan oleh Sedarmayanti (2001: 64) lingkungan kerja adalah "Keseluruhan alat perkakas dan bahan yang dihadapi, lingkungan sekitarnya di mana seseorang bekerja, serta pengaturan kerjanya baik sebagai perseorangan maupun sebagai kelompok".

\section{METODE PENELITIAN}

Untuk menganalisa data digunakan Metode korelasional (hubungan) dengan korelasi product moment. Penelitian akan memprediksi bagaimana hubungan variabel independen terhadap dependen. Dimana sesuai dengan pendapat Pearson sebagaimana dikutip oleh Arikunto (2006:302), untuk membuktikan adanya korelasi dinyatakan dengan koefisen korelasi yang dihitung dengan menggunkan rumus product moment, yaitu :

$$
r_{x y}=\frac{n \sum X Y-\left(\sum X\right)\left(\sum Y\right)}{\sqrt{\left[n \sum X^{2}-\left(\sum X\right)^{2}\right]\left[n \sum Y^{2}-\left(\sum Y\right)^{2}\right]}}
$$

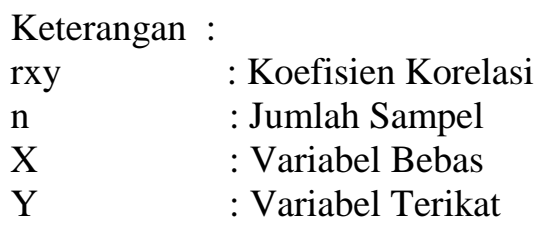

Besar kecilnya Koefisien Korelasi itu terletak antara +1 dan -1 .jika hasil perhitungan positif berarti korelasi variabel yang satu dengan yang lainnya kuat. Untuk mengetahui tinggi rendahnya koefisien korelasi, Sugiyono, (2006:250) menyatakan sebagai berikut

1. $0,00 \mathrm{~s} / \mathrm{d} 0,19=$ Korelasi sangat rendah

2. $0,20 \mathrm{~s} / \mathrm{d} 0,39=$ Korelasi rendah

3. $0,40 \mathrm{~s} / \mathrm{d} 0,59=$ Korelasi sedang

4. $0,60 \mathrm{~s} / \mathrm{d} 0,79=$ Korelasi kuat

5. $0,80 \mathrm{~s} / \mathrm{d} 1,00=$ Korelasi sangat kuat

Untuk melihat garis linier antara pengaruh variabel $\mathrm{X}$ dengan variabel $\mathrm{Y}$, digunakan regresi linear sederhana dengan menggunakan rumus sebagai berikut :

$$
Y=a+b x
$$

Keterangan :

$\mathrm{Y}=$ Variabel Kinerja Pegawai

$\mathrm{a}=$ Konstanta

$\mathrm{b}=$ Koefisien $($ beta $)$ 


$$
\mathrm{X}=\text { Variabel Lingkungan kerja }
$$

Dimana :

$$
\underset{\substack{a \\ n}}{\sum y}-b \cdot \sum x
$$

$$
\begin{array}{r}
\mathrm{N} \cdot \sum \mathrm{XY}-\left(\sum \mathrm{X}\right) \cdot\left(\sum \mathrm{Y}\right) \\
\mathrm{b}=\mathrm{N}^{2} \cdot \mathrm{X}^{2}-\left(\sum \mathrm{X}\right)^{2}
\end{array}
$$

Untuk mengetahui pengaruh Lingkungan kerja terhadap kinerja pegawai, dapat dilakukan dengan menggunakan rumus perhitungan determinasi $\left(\mathrm{r}^{2}\right)$ dengan rumus sebagai berikut :

$$
\mathrm{KD}=\mathrm{r}^{2} \mathrm{X} 100 \%
$$

Selanjutnya setelah diketahui nilai koefisien regresi antara variabel $\mathrm{X}$ dan variabel $\mathrm{Y}$, maka perlu dilakukan pengujian hipotesa dengan menggunakan rumus uji t. Menurut Arikunto (2006:294) rumus uji t adalah sebagai berikut :

$$
t=\frac{\sqrt{r^{2}(n-2)}}{\sqrt{\left(1-r^{2}\right)}}
$$

$\mathrm{Df}=2$

Keterangan :

$\mathrm{r}$ : Korelasi X dan Y yang ditemukan

$\mathrm{n} \quad$ : Jumlah Sampel

$\mathrm{t}: \mathrm{t}_{\text {Hitung }}$ yang selanjutnya dikonsultasikan dengan $\mathrm{t}_{\text {Tabel }}$ dengan taraf signifikan 0,05

$\%$ uji dua pihak dan $\mathrm{dk}=\mathrm{n}-2$

Dengan ketentuan :

Ha : Diterima, apabila t hitung $\geq \mathrm{t}$ tabel, danHo Ditolak.

Ho : Diterima, apabila t hitung $\leq \mathrm{t}$ tabeldan Ha Ditolak

\section{PEMBAHASAN}

Sesuai dengan rumusan hipotesis penelitian ini, yaitu adanya pengaruh penerapan lingkungan kerjaterhadap kinerja pegawaipada Kantor Sekretariat Dewan Perwakilan Rakyat Daerah Kota Sibolga.Untuk membuktikan jawaban hipotesis yang penulis kemukakan "diterima" atau "ditolak" dapat diketahui dari hasil perhitungan uji t (parsial) dari koefisien analisa regresi sederhana antara variabel X (lingkungan kerja) dan variabel Y (Kinerja pegawai) berikut ini.

Berdasarkan hasil penilaian rata-rata hasil jawaban responden setiap item variabel $\mathrm{X}$ (lingkungan kerja) dan variabel Y (kinerja pegawai) tersebut diatas, maka untuk menentukan 
nilai kolerasinya, dalam penelitian ini menggunakan metode korelasi product moment. Selanjutnya data-data pada tabel variabel lingkungan kerja ( X ) dan variabel Kinerja pegawai ( Y ) dimasukkan pada tabel berikut :

Tabel 1. Perhitungan koefisien kolerasi pengaruh lingkungan kerja Terhadap Kinerja pegawai

\begin{tabular}{|c|c|c|c|c|c|}
\hline Resp. & $\mathrm{X}$ & $\mathrm{Y}$ & $\mathrm{X}^{2}$ & $\mathrm{Y}^{2}$ & $\mathrm{XY}$ \\
\hline 1 & 42 & 39 & 1764 & 1521 & 1638 \\
\hline 2 & 41 & 39 & 1681 & 1521 & 1599 \\
\hline 3 & 44 & 42 & 1936 & 1764 & 1848 \\
\hline 4 & 37 & 34 & 1369 & 1156 & 1258 \\
\hline 5 & 38 & 36 & 1296 & 1296 & 1296 \\
\hline 6 & 34 & 33 & 1156 & 1089 & 1122 \\
\hline 7 & 37 & 37 & 1369 & 1369 & 1369 \\
\hline 8 & 37 & 36 & 1369 & 1296 & 1332 \\
\hline 9 & 34 & 34 & 1156 & 1156 & 1156 \\
\hline 10 & 39 & 36 & 1521 & 1296 & 1404 \\
\hline 11 & 42 & 39 & 1764 & 1521 & 1638 \\
\hline 12 & 41 & 39 & 1681 & 1521 & 1599 \\
\hline 13 & 44 & 42 & 1936 & 1764 & 1848 \\
\hline 14 & 37 & 34 & 1369 & 1156 & 1258 \\
\hline 15 & 38 & 36 & 1296 & 1296 & 1296 \\
\hline 16 & 34 & 33 & 1156 & 1089 & 1122 \\
\hline 17 & 37 & 37 & 1369 & 1369 & 1369 \\
\hline 18 & 37 & 36 & 1369 & 1296 & 1332 \\
\hline 19 & 34 & 34 & 1156 & 1156 & 1156 \\
\hline 20 & 39 & 36 & 1521 & 1296 & 1404 \\
\hline 21 & 42 & 39 & 1764 & 1521 & 1638 \\
\hline 22 & 41 & 39 & 1681 & 1521 & 1599 \\
\hline 23 & 42 & 42 & 1764 & 1681 & 1722 \\
\hline 24 & 41 & 34 & 1681 & 1225 & 1435 \\
\hline 25 & 44 & 36 & 1936 & 1296 & 1584 \\
\hline 26 & 37 & 33 & 1369 & 1089 & 1221 \\
\hline 27 & 38 & 37 & 1444 & 1521 & 1482 \\
\hline 28 & 34 & 36 & 1156 & 1296 & 1224 \\
\hline 29 & 37 & 34 & 1369 & 1156 & 1258 \\
\hline 30 & 37 & 36 & 1369 & 1296 & 1332 \\
\hline 31 & 34 & 39 & 1156 & 1521 & 1326 \\
\hline 32 & 39 & 39 & 1521 & 1521 & 1521 \\
\hline 33 & 37 & 36 & 1369 & 1298 & \\
\hline & 1269 & 1212 & 49109 & 44730 & 46787 \\
\hline
\end{tabular}

Sumber: Angket penelitian diolah, 2016 
Dari tabel diatas diperoleh :

$$
\begin{aligned}
& \mathrm{N}=33 \\
& \Sigma \mathrm{X}=1269 \\
& \Sigma \mathrm{Y}=1212 \\
& \Sigma \mathrm{X}^{2}=49.109 \\
& \Sigma \mathrm{Y}^{2}=44.730 \\
& \Sigma \mathrm{XY}=46.787
\end{aligned}
$$

Untuk mengetahui apakah ada kolerasi antara lingkungan kerja (variabel X) dan Kinerja pegawai (variabel Y), maka nilai-nilai dari tabel tersebut diatas dapat dimasukkan ke dalam rumus sebagai berikut :

$$
\begin{aligned}
& \mathrm{rxy}=\quad \mathrm{n} \Sigma \mathrm{xy}-(\Sigma \mathrm{x})(\Sigma \mathrm{y}) \\
& \sqrt[33]{\left\{n \Sigma x^{2}-(\Sigma x)^{2}\right\} \cdot\left\{n \Sigma y^{2}-(\Sigma y)^{2}\right.} \\
& 33(46.787)-(1269)(1212) \\
& =\sqrt{3} \widehat{\left.3(49109)-(1269)^{2}\right\}\left\{33(44.730)-(1212)^{2}\right\}} \\
& =\quad \frac{1.543 .971-1.538 .028}{(\sqrt[10]{236)(7.146)}} \\
& 5.943 \\
& =\quad 73.146 .45 \\
& =8.552,57 \\
& =0,69
\end{aligned}
$$

Dari perhitungan diatas dapat diketahui bahwa terdapat hubungan yang positif antara lingkungan kerja dengan Kinerja pegawai sebesar 0,69. Untuk dapat memberi interpretasi terhadap kuatnya hubungan itu, maka dapat digunakan pedoman pada tabel berikut :

Tabel 2. Tingkat interpretasi nilai $\mathrm{r}$

\begin{tabular}{|l|l|}
\hline \multicolumn{1}{|c|}{ Besarnya nilai r } & \multicolumn{1}{|c|}{ Interpretasi } \\
\hline Antara 0,800 sampai dengan 1,00 & Tinggi \\
Antara 0,600 sampai dengan 0,800 & Cukup \\
Antara 0,400 sampai dengan 0,600 & Agak Rendah \\
Antara 0,200 sampai dengan 0,400 & Rendah \\
Antara 0,000 sampai dengan 0,200 & Sangat rendah \\
\hline
\end{tabular}

Sumber : Suharsimi Arikunto ( $2006: 245$ ) 
Berdasarkan tabel 2 tersebut, maka koefisien kolerasi yang ditemukan sebesar 0,69 termasuk kategori cukup. Jadi terdapat hubungan tinggi dan positif antara pengaruh lingkungan kerja dengan Kinerja pegawai pada Kantor Sekretariat Dewan Perwakilan Rakyat Daerah Kota Sibolga.

Selanjutnya untuk mengetahui pengaruh, maka untuk membuktikannya digunakan rumus regresi linier sederhana seperti pada persamaan 2, dimana $y=a+b x$.

$$
\begin{aligned}
& \text { Dimana } \mathrm{b}=\mathrm{n}\left(\sum \mathrm{xy}\right)-\left(\sum \mathrm{x}\right)\left(\sum \mathrm{y}\right) \\
& \mathrm{n}\left(\sum \mathrm{x}^{2}\right)-\left(\sum \mathrm{x}\right)^{2} \\
& \mathrm{~b}=\quad 33(46.787)-(1269)(1212) \\
& 33(49.109)-1269^{2} \\
& =\quad 1.543 .971-1.538 .028 \\
& 1.620 .597-1.610 .361 \\
& =5943 / 10236 \\
& =0,58 \\
& \mathrm{a}=\left(\sum \mathrm{y}-\mathrm{b} \sum \mathrm{x}\right) / \mathrm{n} \\
& =\underline{1212-(0,58)(1269)} \\
& 33 \\
& =475,78 / 33=14,40
\end{aligned}
$$

Dari perhitungan diatas dapat diperoleh persamaan regresi sebagai berikut : Y $=14,40+$ $0,58 \mathrm{X}$, hal ini berarti bahwa yang terjadi pengaruh pada variabel terikat (kinerja pegawai) ditentukan oleh variabel bebas (lingkungan kerja) dengan koefisien regresi sebesar 0,58 atau $58 \%$, dimana apabila ditambahkan satu satuan variabel $\mathrm{X}$ (lingkungan kerja) atau nilai tertentu maka akan menambah peningkatan variabel $\mathrm{Y}$ (Kinerja pegawai) sebesar koefisien regresi 0,58 atau dikalikan dengan nilai tertentu tersebut.

Setelah nilai koefisien regresi diketahui, maka langkah selanjutnya adalah mencari nilai t hitung dengan tujuan untuk mengetahui apakah hipotesa yang diajukan ditolak atau diterima dapat diketahui dengan cara-cara sebagai berikut :

1. Membandingkan antara nilai thitung dengan nilai $t$ tabel dengan ketentuan :

a. Apabila t hitung lebih besar dari t tabel maka hipotesis alternatif ( $\mathrm{Ha}$ ) diterima dan hipotesis $\mathrm{O}(\mathrm{Ho})$ ditolak.

b. Apabila nilai t hitung lebih kecil dari t tabel maka hipotesis alternatif (Ha) ditolak dan Hipotesis (Ho) diterima.

2. Mencari nilai derajat kebebasan ( $\mathrm{dk})$, yaitu $\mathrm{dk}=2$, dalam hal ini $\mathrm{n}=33$, maka $\mathrm{dk}=33-2$ $=31$.

3. Setelah nilai dk diketahui maka nilai $\mathrm{t}$ tabel ( nilainya telah diketahui dalam tabel $\mathrm{t}$ ) untuk dk 30 pada taraf signifikan 0,05 adalah sebesar 2,0395 
Untuk menguji apakah koefisien kolerasi yang didapat signifikan atau tidak, perlu dilakukan pengujian hipotesis dengan menggunakan rumus :

$$
\begin{aligned}
& t=r \frac{\sqrt{(n-1)}}{\sqrt{1-r^{2}}} \\
& =\frac{0,69 \sqrt{ }(33-1)}{\sqrt{1-(0,69)^{2}}} \\
& =\frac{3,9308}{\sqrt{0,5239}} \\
& =3,9308 / 0,7238 \\
& =5,4307
\end{aligned}
$$

Dari perhitungan tersebut diatas, maka selanjutnya nialai t hitung dibandingkan dengan nilai $\mathrm{t}$ tabel. Setelah dibandingkan didapat hasil bahwa nilai $\mathrm{t}$ hitung lebih besar dari nilai $\mathrm{t}$ tabel atau 5,4307> 2,0395 Karena nilai t hitumg lebih besar dari nilai t tabel , maka hipotesis alternatif ( $\mathrm{Ha}$ ) diterima

Selanjutnya untuk mengetahui besarnya pengaruh lingkungan kerjaterhadap Kinerja pegawai pada Kantor Sekretariat Dewan Perwakilan Rakyat Daerah Kota Sibolga dapat dilakukan dengan menggunakan rumus koefisien determinasi $\left(\mathrm{r}^{2}\right)$ sebagai berikut :

$$
\begin{aligned}
\mathrm{KD} & =\mathrm{r}^{2} \times 100 \% \\
& =0,69^{2} \times 100 \% \\
& =48 \%
\end{aligned}
$$

Dari perhitungan diatas dapat diperoleh koefisien determinasi sebesar $48 \%$, hal ini berarti bahwa yang terjadi pada variasi variabel terikat (Kinerja pegawai) $48 \%$ ditentukan oleh variabel bebas (lingkungan kerja) dan sisanya sebesar $52 \%$ ditentukan oleh faktor lain yang tidak dibahas oleh penulis.Dengan demikian hipotesis yang dirumuskan dalam penelitian ini dapat diterima kebenarannya berdasarkan hasil analisis uji hipotesis (uji t / parsial) diatas dimana hipotesis kerja (Ha) diterima.

\section{KESIMPULAN DAN SARAN}

\section{A. Kesimpulan}

Berdasarkan uraian hasil penelitian tentang pengaruh lingkungan kerja terhadapkinerja pegawai pada Kantor Sekretariat Dewan Perwakilan Rakyat Daerah Kota Sibolga, maka dapat disimpulkan sebagai berikut:

1. Secara keseluruhan nilai rata-rata disiplin pegawai dan Kinerja pegawai Kantor Sekretariat Dewan Perwakilan Rakyat Daerah Kota Sibolga mendapat nilai rata-rata sebesar 3,85 dan 3,67 yang dikategorikan baik.

2. Berdasarkan koefisien kolerasi yang diperoleh sebesar 0,69 , maka dapat dikatakan bahwa terdapat hubungan yang cukup dan positif sebesar 0,69 antara penerapanlingkungan kerja dalam usaha mewujudkan Kinerja pegawai pada Kantor Sekretariat Dewan Perwakilan Rakyat Daerah Kota Sibolga.

3. Persamaan regresi yang diperoleh $\mathrm{Y}=14,40+0,58 \mathrm{X}$ yang menunjukkan pengaruh lingkungan kerja dalam meningkatkan kinerja pegawai akan bertambah sebesar koefisien $(0,58)$ apabila variabel lingkungan kerja ditambah dengan satu satuan. 
4. Berdasarkan uji t yang dilakukan terhadap hipotesis yang diajukan dapat diterima, dimana $\mathrm{t}$ hitung lebih besar dari t tabel yaitu 5,4307 > 2,0395 yang berarti ada pengaruh penerapan lingkungan kerjadalam usaha mewujudkan Kinerja pegawai pada Kantor Sekretariat Dewan Perwakilan Rakyat Daerah Kota Sibolga.

5. Berdasarkan analisis Koefisien Determinasi yang diperoleh sebesar 0,48 $=48 \%$, hal ini bermakna bahwa kemampuan model dalam menjelaskan variasi variabel kinerja pegawai oleh variabel lingkungan kerja sebesar $48 \%$ pada Kantor Sekretariat Dewan Perwakilan Rakyat Daerah Kota Sibolga, sedangkan sisanya dijelaskan variabel lain yang tidak dimasukkan dalam model sebesar $52 \%$.

B. Saran

Berdasarkan hasil analisis dan kesimpulan, diajukan beberapa saran sebagai berikut :

1. Pimpinan Kantor Sekretariat Dewan Perwakilan Rakyat Daerah Kota Sibolga perlu mengembangkanpenerapan lingkungan kerjauntuk diisi calon pegawai yang sesuai sehingga kinerja pegawaipegawai lebih meningkat.

2. Untuk meningkatkan Kinerja pegawai, maka pimpinan diharapkan untuk meningkatkan keahlian pegawai sehingga pembagian dan penyelesaian pekerjaan/ tugas sesuai dengan lingkungan kerja.

3. Pimpinan lebih fokus untuk pelatihan dan koordinasi antar bagian agar dapat mengefektifkan pelaksanaan tugas untuk menghindari kerugian akibat tidak efektifnya lingkungan kerja dalam melaksanakan pekerjaan.

\section{REFERENSI}

Arikunto, Suharsimi, 2006. Prosedur Penelitian Suatu Pendekatan Praktik, Cetakan Ketiga Belas, Jakarta, Rhineka Cipta

Fadel, 2009, Manajemen Personalia, Erlangga , Jakarta, Tarsito, Bandung.

Furchan Arif, 2000, Penggantar Metode Penelitian Kualitatif, Surabaya,Usaha Nasional

Handoko, T. Hani. 2007, Manajemen Sumber Daya Manusia , BPFE, Yogjakarta

Hasibuan S.P Malayu, 2009,Manajemen Sumber Daya Manusia, Dasar dan Kunci Keberhasilan, Jakarta:Gunung Agung

Mangkuprawira, A.A. Anwar Prabu, 2009 , Evaluasi Kinerja Sumber Daya Manusia, Relika Aditama, Bandung

Nitisemito, Alex S. 2002. Manajemen Personalia. Edisis Revisi. Dialihbahasakan oleh Ghalia Indonesia. Jakarta: Balai Aksara dan Yudhistira.

Kreitner, Robert dan Angelo Kinicki, 2003, Organizational Behavior, Perilaku Organisasi, Penerjemah Erly Suandy, Salemba Empat, Jakarta. 
Mangkunegara, A.A. Anwar Prabu, 2005, Manajemen Sumber Daya Manusia Perusahaan, Cetakan keenam, Remaja Rosdakarya, Bandung,

Mathis, Robert L. dan John H. Jackson, 2001, Manajemen Sumber Daya Manusia, PT. Salemba Emban Patria, Jakarta.

Robbins, Sethepen P. dan Timothy A. Judje, 2008, Organizational Behavior, Perilaku Organisasi, Penerjemah Diana Angelika Ria Cahyani dan Abdul Rasyid, Salemba Empat, Jakarta.

Ranuprojo, Heidjrachman dan Suad Husnan. 2009. Manajemen Personalia. Yogyakarta: BPFE.

Rivai, Veithzal, 2004, Manajemen Sumber Daya Manusia dari Teori ke Praktek, PT. Raja Grafindo Persada, Jakarta.

Sedarmayanti, 2001, Sumber Daya Manusia dan Produktifitas Kerja, Tarsito, Bandung

Sopiah. 2008. Perilaku Organisasi.Yogyakarta: Andi.

STIE Al-Washliyah Sibolga / Tapanuli Tengah, 2015, Pedoman Penulisan dan Penyusunan Skripsi / Laporan Penelitian. Sibolga : STIE Al-Washliyah Sibolga / Tapanuli Tengah

Sugiyono, 2006, Statistika Untuk Penelitian, Bandung : Alfabeta

Widjaja, 2006, Manajemen Kinerja, Edisi Kedua, Penerbit Raja Grafindo Persada: Jakarta

STIE Al-Washliyah Sibolga/Tapanuli Tengah, 2015, Pedoman Penulisan dan Penyusunan Skripsi, Sibolga

The Liang Gie, 2008,Pertumbuhan Pemerintahan Daerah di Negara Republik Indonesia.Jakarta : Gunung Agung

Tingkilisan Hessel S, 2005, Manajemen Pelayanan Publik, Jakarta: Grassindo

Zauhar, 2006, Hukum Administrasi Pemerintahan di Daerah. Jakarta : Sinar Grafika. 